\title{
DIAGNÓSTICO POLÍTICO-GERENCIAL DOS SERVIÇOS DE SANEAMENTO BÁSICO EM MUNICÍPIOS GOIANOS TREZE ANOS APÓS A PROMULGAÇÃO DA LEI № 11.445/2007
}

\author{
Leandro de Almeida Jeronimo \\ Instituto Federal de Educação, Ciência e Tecnologia de Goiás, Brasil \\ leandro.eng.ambiental@gmail.com \\ Rosana Gonçalves Barros \\ Instituto Federal de Educação, Ciência e Tecnologia de Goiás, Brasil \\ rosana.ifg@gmail.com \\ Viniciu Fagundes Barbara \\ Instituto Federal de Educação, Ciência e Tecnologia de Goiás, Brasil \\ viniciu.fagundes@gmail.com
}

\begin{abstract}
RESUMO
Pesquisas sobre saneamento básico ainda são escassas no Brasil. O presente estudo objetivou diagnosticar a realidade político-gerencial desses serviços em 55 municípios goianos com até 50.000 habitantes, identificando as principais deficiências no atendimento às diretrizes estabelecidas pela Política Nacional de Saneamento Básico. Para tanto, foi desenvolvida uma pesquisa descritiva-exploratória fundamentada na aplicação de questionários semiestruturados durante o período de outubro/2017 a abril/2019, tendo sido avaliadas as seguintes categorias de análise: instituições prestadoras dos serviços e existência/características das Políticas e Planos Municipais de Saneamento Básico; de consórcios, conselhos, programas e fundos de saneamento; de ações de educação sanitária; de procedimentos avaliativos e de sistemas de informação. Restou evidenciado que apesar de alguns avanços, todos os municípios estudados ainda se encontram atrasados na busca pela universalização do acesso e pela integralidade na oferta dos serviços. Mesmo no que se refere às Políticas e Planos Municipais de Saneamento Básico, pilares basilares do setor, as lacunas identificadas são profundas, notadamente em termos de controle social. É fundamental que os gestores públicos e a sociedade civil organizada assumam seus papéis nos contextos locais, visando a efetivação dos serviços de saneamento, sob pena de manterem a saúde pública e o equilíbrio ambiental em risco.
\end{abstract}

Palavras-chave: Condições sanitárias. Planos municipais de saneamento básico. Governança em saneamento. Sustentabilidade urbana.

\section{POLITICAL AND MANAGERIAL DIAGNOSIS OF BASIC SANITATION SERVICES IN 55 MUNICIPALITIES IN GOIÁS THIRTEEN YEARS AFTER THE ENACTMENT OF LAW 11,445/2007}

\begin{abstract}
Research on basic sanitation is still scarce in Brazil. The present study aimed to diagnose the political-managerial reality of these services in 55 municipalities in Goiás with up to 50,000 inhabitants, identifying the main deficiencies in meeting the guidelines established by the National Policy on Basic Sanitation. For this, a descriptive-exploratory research was developed based on the application of semi-structured questionnaires during the period from october/2017 to april/2019, having been evaluated the following categories of analysis: institutions providing services and existence/characteristics of Municipal Sanitation Policies and Plans; consortia, councils, programs and sanitation funds; sanitation education actions; evaluation procedures and information systems. It has become evident that despite some advances, all the studied municipalities are still behind in the search for the universalization of access and for the integrality in the offer of services. Even with regard to Municipal Sanitation Policies and Plans, the basic pillars of the sector, the gaps identified are deep, especially in terms of social control. It is essential that public managers and organized civil society assume their roles in the local contexts, aiming at the effectiveness of sanitation services, under penalty of keeping public health and the environmental balance at risk.
\end{abstract}

Keywords: Sanitary conditions. municipal basic sanitation plans. Sanitation governance. Urban sustainability. 


\section{INTRODUÇÃO}

O saneamento básico é condição indispensável à proteção do meio ambiente e da saúde pública, à redução das desigualdades sociais e ao desenvolvimento econômico (MACIEL; FELIPE; LIMA, 2015; CRISPIM et al., 2016; REIS et al., 2017). Com o estabelecimento dos Objetivos do Desenvolvimento Sustentável (ODS) pela Organização das Nações Unidas (ONU), que tiveram a adesão de 192 países, os esforços globais voltados para a ampliação do acesso aos serviços sanitários se intensificaram nos últimos anos (ZHOU et al., 2018), especialmente em países como Índia e China e em nações africanas e das Américas Central e do Sul. Devido aos novos elementos de saúde pública adicionados ao contexto global, como o recente surto de Síndrome Respiratória Aguda Grave, cujo vírus causador (COVID-19) aparenta ter potencial para disseminação por esgotos (SODRÉ et al., 2020), a demanda por saneamento básico se mostra urgente.

No Brasil, o Estado teve a primeira grande iniciativa em relação ao setor de saneamento apenas em 1969, com a instituição do Plano Nacional de Saneamento (PLANASA) (REZENDE e HELLER, 2008; LEONETI; PRADO; OLIVEIRA, 2011; LIMA NETO e SANTOS, 2012). Posteriormente, com a promulgação da Constituição Federal de 1988, a competência de prestação dos serviços, antes centralizada, passou a ser divida pelas três esferas governamentais (SOUSA; SOUSA; ALVARES, 2015). Instituída pela Lei Federal no 11.445, de 05 de janeiro de 2007 (BRASIL, 2007), a atual Política Nacional de Saneamento Básico (PNSB) estabeleceu os princípios da universalização do acesso e da integralidade da oferta dos serviços (CARVALHO e ADAS, 2012; ARAÚJO et al., 2016). Aprovado pelo Governo Federal em 2013, o Plano Nacional de Saneamento Básico (PLANSAB) instituiu as diretrizes complementares para a elaboração das políticas e dos planos voltados ao setor (SILVEIRA; HELLER; REZENDE, 2013), tendo definido metas de curto, médio e longo prazo para a efetiva implementação dos serviços na integralidade das Unidades Federativas (UFs).

Apesar dos inquestionáveis avanços regulatórios ocorridos nos últimos anos e embora o setor venha experimentando um novo ciclo no país, que tende a ser potencializado com a recente aprovação do Novo Marco Legal do Saneamento (BRASIL, 2020) e a retomada de investimentos, essa trajetória tem revelado tensões e contradições inerentes ao contexto político-ideológico caracterizadas por vínculos profundos com a estrutura de poder e as relações sociais capitalistas, resultando nos baixos índices de saneamento básico ainda observados no país (SILVA e MOITA NETO, 2019), mesmo após transcorridos treze anos da promulgação da PNSB. Especificamente em Goiás, somente há pouco tempo o Estado passou a contar com diretrizes mais acuradas voltadas ao setor, com o advento da Política Estadual de Saneamento Básico (PESB), instituída pela Lei no 19.453/2016 (BRASIL, 2016).

De acordo com Teixeira et al. (2014), diante das preocupantes deficiências que o setor ainda apresenta no Brasil, a implementação de melhorias nas condições sanitárias visando à promoção da saúde pública e à manutenção do equilíbrio ambiental mostra-se urgente, notadamente no âmbito municipal. De acordo com Galvão Júnior; Sobrinho; Silva (2012) e FUNASA (2018), a Lei 11.445/2007 determina que o planejamento dos serviços de saneamento básico na esfera local deve advir do Plano Municipal de Saneamento Básico (PMSB), elaborado por cada Prefeitura, estudo que deve conter as diretrizes para a organização dos serviços, considerando as funções de gestão, desde o planejamento até a prestação, submetidos à regulação, à fiscalização e ao controle social. Contudo, apesar dos comprovados benefícios sociais e ambientais associados à existência de saneamento básico, particularmente em termos de saúde pública e de proteção das coleções hídricas (LISBOA; HELLER; SILVEIRA, 2013), os gestores de parte considerável dos municípios brasileiros, em especial dos de pequeno porte, ainda sequer dispõem de diagnósticos atualizados e pormenorizados das condições desses serviços em seus respectivos territórios.

Segundo Heller e Nascimento (2005), Yévenes-Subriate (2010) e Lima; Torres; Oliveira Filho (2017), é importante que os avanços do setor sejam embasados em estudos acadêmicos que abordem diagnósticos específicos sobre as diferentes realidades locais, informações que podem ser utilizadas em articulações político-gerenciais voltadas para a consolidação de mudanças efetivas no atual quadro sanitário nacional. Todavia, os autores complementam que embora trabalhos com esse enfoque possam ser considerados pontos iniciais para o subsídio de ações de planejamento voltadas para a correção ou eliminação dos problemas de saneamento básico existentes, reduzindo improvisações e decisões emergenciais - comuns no âmbito de administrações públicas municipais -, pesquisas dessa natureza ainda são escassas no Brasil. Heller e Nascimento (2005) complementam que a redução da exclusão social e a melhoria dos níveis de cidadania associados à falta de saneamento passam pela produção de conhecimento especializado, pois é por intermédio da identificação dos efeitos possíveis e desejáveis desses serviços que efetivamente se pode balizar escolhas e realizar avaliações para fins gerenciais.

$\begin{array}{llllll}\text { Caminhos de Geografia } & \text { Uberlândia-MG } & \text { v. 23, n. } 85 & \text { fev./2022 } & \text { p. 69-87 } & \text { Página } 70\end{array}$


Adicionalmente, destacam que a partir de um referencial científico é possível desencadear um debate sobre a distância entre a atual realidade do setor e o padrão idealizado, identificando lacunas e necessidades e, como decorrência, estabelecendo diretrizes gerenciais voltadas para a mudança da realidade investigada, principalmente no caso de Goiás, detentor de profundas e variadas realidades sanitárias.

Magalhães et al. (2015) e Araújo et al. (2016) destacam que um dos primeiros passos para a melhor compreensão da situação sanitária de uma determinada região é realizar o levantamento detalhado do atendimento efetivo e da realidade fática, no sentido amplo, dos serviços prestados, tendo em vista que a avaliação de políticas públicas e a análise das variáveis relacionadas ao seu desempenho são indispensáveis para a concepção dos processos fomentadores que poderão resultar na mudança das realidades locais. Nesse contexto, o presente trabalho objetivou realizar um diagnóstico atualizado da realidade político-gerencial dos serviços de saneamento básico em 55 municípios de pequeno porte localizados no estado de Goiás, Brasil, identificando as principais deficiências no atendimento às diretrizes estabelecidas pela Política Nacional de Saneamento Básico.

\section{METODOLOGIA}

A presente investigação se baseou em metodologia qualitativa classificada como descritiva-exploratória (ZIKMUND, 2000; COOPER e SCHINDLER, 2003; GIL, 2008; PRODANOV e FREITAS, 2013), tendo se concentrado na identificação das características dos serviços de saneamento de 55 municípios goianos com população total de até 50 mil habitantes (Figura 1), perfazendo 8,31\% (575.290) do total do Estado (IBGE, 2010). Goiás possui área de $340.103,467 \mathrm{~km}^{2}$ e é o segundo maior e mais populoso da região Centro-Oeste, contando com 6.921.161 habitantes (IBGE, 2017).

Figura 1 - Estado de Goiás: Distribuição dos 55 municípios contemplados na pesquisa, incluindo suas respectivas populações, que perfazem 8,31\% do total do Estado, 2019.

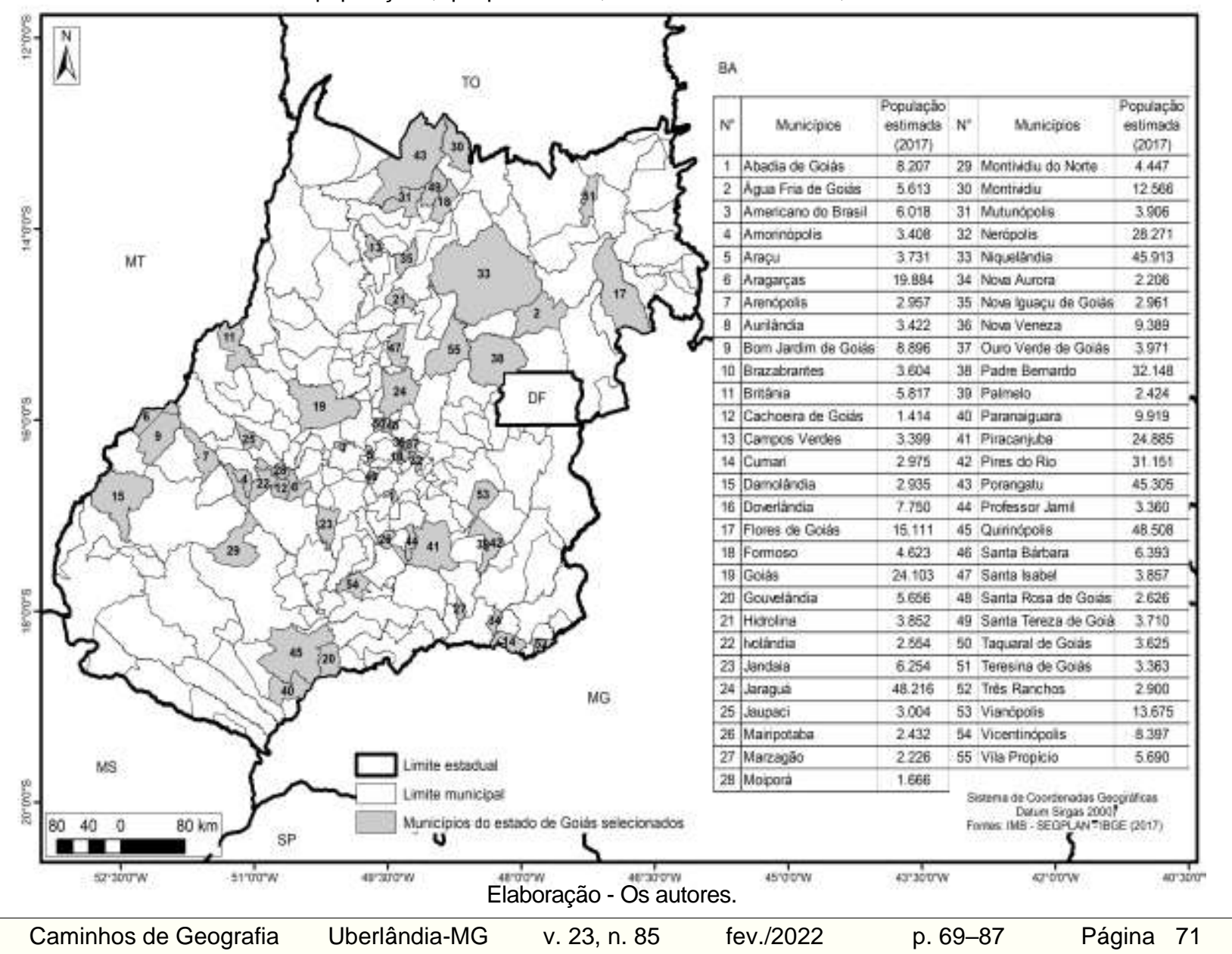


Primeiramente, foram obtidos dados secundários referentes aos índices oficiais de atendimento das populações dos municípios pesquisados mediante levantamentos em sites de instituições oficiais com atuação em saneamento básico, como o Instituto Brasileiro de Geografia e Estatística (IBGE) e o Sistema Nacional de Informações sobre Saneamento (SNIS), assim como realizado por outros pesquisadores (LEONETI; PRADO; OLIVEIRA, 2011; CRISPIM et al., 2016; LIMA et al., 2017; LIMA; ARRUDA; SCALIZE, 2019).

Para a geração dos dados primários, profissionais da área de saneamento que exercem suas funções no âmbito municipal responderam a questionários semiestruturados concebidos com base no Termo de Referência da Fundação Nacional da Saúde (FUNASA) para elaboração de Planos Municipais de Saneamento Básico, em consonância com o Termo de Execução Descentralizada (TED) ㄲo 17/2014, firmado com o Instituto Federal de Educação, Ciência e Tecnologia de Goiás (IFG). Para tanto, foram realizadas visitas aos municípios no período de outubro/2017 a abril/2019 para obtenção de informações referentes às seguintes categorias de análise: instituições responsáveis pela prestação dos serviços de saneamento básico; existência/características das Políticas (PoMSB) e dos PMSBs; de consórcios, conselhos, programas e fundos de saneamento; de ações de educação sanitária; de procedimentos de avaliação dos serviços e de sistemas de informação. Por fim, os dados obtidos foram organizados e discutidos (SACHO e HORA, 2017).

\section{RESULTADOS E DISCUSSÃO}

A Figura 2 (a-c) ilustra os índices de cobertura das populações dos 55 municípios pesquisados em relação aos serviços de abastecimento de água, esgotamento sanitário e coleta de resíduos sólidos. Não foi possível analisar a cobertura de drenagem de águas pluviais per capita devido à inexistência de dados oficiais (SOUZA, 2013). De acordo com SNIS (2017), embora 93,0\% da população brasileira conte com abastecimento de água potável, em oito dos municípios pesquisados (14,6\%: Paranaiguara, Cachoeira de Goiás, Vicentinópolis, Padre Bernardo, Santa Isabel, Vila Propício, Flores de Goiás e Montividiu; Figura 2a) esse percentual é consideravelmente inferior, variando entre $20,0 \%$ e $50,0 \%$, ficando a cargo de cada família providenciar o abastecimento hídrico domiciliar, o que geralmente é feito por intermédio de poços rasos. Nos 47 municípios restantes (85,4\%) o índice está acima de 60,0\%, variando entre $80,0 \%$ e 100,0\%, como em Porangatu, Santa Tereza de Goiás, Campos Verdes, Britânia, Jaraguá, Aragarças, Nerópolis, Araçu, Doverlândia e Montividiu do Norte.

De acordo com Andrade et al. (2019), o abastecimento de água com qualidade é uma necessidade humana básica, devendo ser contínuo e suficiente para atender às demandas diárias. Lisboa; Heller; Silveira (2013) destacam que a disponibilidade desse recurso em quantidade e qualidade adequadas constitui fator de prevenção de diversas doenças de transmissão hídrica, como diarreia, amebíase, cólera, leptospirose, disenteria bacteriana, hepatite A, esquistossomose e febre tifoide. Segundo Giatti (2007), que pesquisou a relação entre abastecimento de água e problemas de saúde pública na Amazônia brasileira, os problemas dessa natureza que ocorrem no Brasil são resultado da baixa eficiência no fornecimento hídrico associada a elevados índices de perdas, sendo pouco salutar a captação em poços rasos, principalmente em áreas urbanas, devido ao alto risco de contaminação das águas subterrâneas, notadamente por esgotos advindos de fossas negras.

Em termos de esgotamento sanitário, o serviço é o que apresenta os menores índices de cobertura nos municípios goianos pesquisados (Figura 2b). Segundo SNIS (2017), cerca de 100 milhões de brasileiros ainda não são contemplados com a coleta de águas residuárias, e apenas $45,0 \%$ dos esgotos coletados são tratados. No caso do presente estudo, verificou-se que nenhum dos municípios possui $100,0 \%$ de cobertura de coleta, sendo que somente Britânia e Quirinópolis (3,6\%) possuem entre $70 \%$ e $90 \%$ da população atendida. Piracanjuba conta com índices entre 60,0\% e 70,0\%, Goiás com valores entre 50,0\% e $60,0 \%$, e Niquelândia, Padre Bernardo, Jaraguá, Abadia de Goiás, Palmelo, Pires do Rio e Montividiu do Norte com índices variando de $40,0 \%$ a $50,0 \%$ de cobertura. Os demais municípios (44, ou seja, $80,0 \%$ ) apresentam índices inferiores.

Segundo Tischer (2017), a deficiência na cobertura dos serviços de esgotamento sanitário onera os custos com tratamento de água para fins de abastecimento, além de favorecer o surgimento de problemas ambientais e de saúde pública. De acordo com Leoneti; Prado; Oliveira (2011), Evaristo et al. (2017), Sacho e Hora (2017), Mendes e Barcellos (2018) e Monteiro et al. (2018), enfermidades básicas estão diretamente relacionadas à precariedade ou à inexistência de esgotamento sanitário, sendo fundamental a universalização da coleta e do tratamento eficiente para garantia da manutenção da saúde pública e para

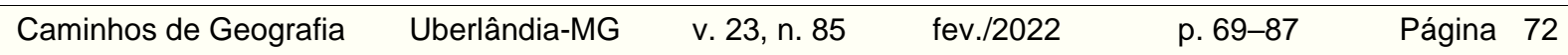


a economia de recursos com internações e tratamentos de enfermidades. Para Siqueira et al. (2017), doenças provocadas pela disposição inadequada de esgotos estão entre as principais causas de morbimortalidade em países com economias em desenvolvimento, como o Brasil.

Figura 2 - Estado de Goiás: Índices da população dos 55 municípios pesquisados atendida pelos serviços de a) abastecimento de água, b) esgotamento sanitário e c) coleta de resíduos sólidos, 2017.
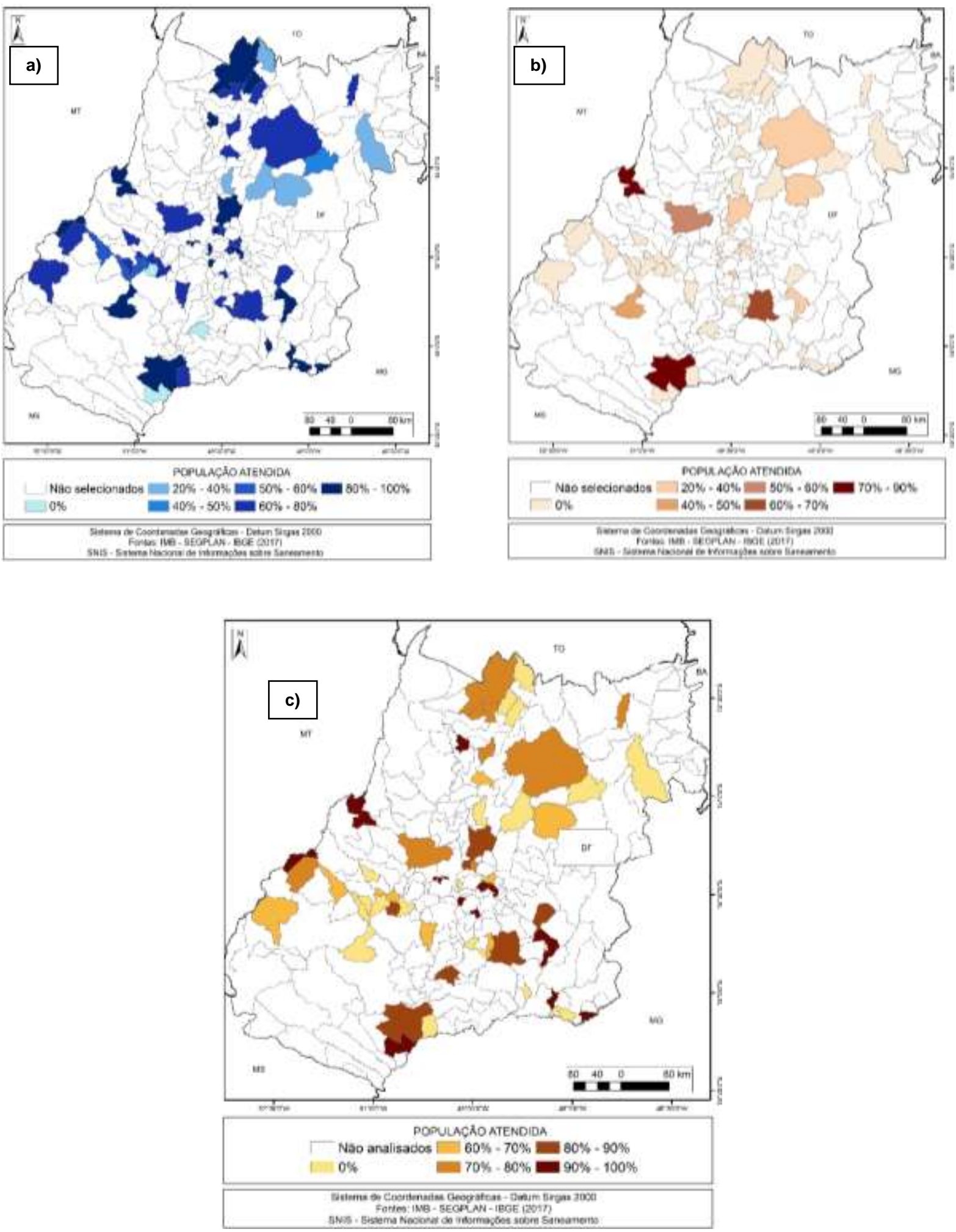

Fonte - Adaptado de SNIS (2017). 
Corroboram com esse entendimento Paiva e Souza (2018), que desenvolveram uma análise associativa entre condições socioeconômicas, sanitárias e de atenção básica e a morbidade hospitalar por doenças de veiculação hídrica no Brasil. Seus resultados demonstraram que, tomando-se como base os dados de 2013, 57.574 (cerca de 16,3\%) das internações por doenças selecionadas no país poderiam ter sido evitadas se as condições de esgotamento sanitário fossem adequadas. Adicionalmente, os autores comprovaram que os gastos com o tratamento dessas enfermidades por parte do poder público foram elevados. Teixeira et al. (2014) também demonstraram que a falta de condições sanitárias foi responsável por 13.449 óbitos/ano, em média, no período de 2001 a 2009 no Brasil, sendo a dengue, a hepatite, a esquistossomose e a leptospirose as principais enfermidades notificadas compulsoriamente, todas associadas à falta/precariedade de serviços de saneamento. Os autores destacam, ainda, que a despesa total do Sistema Único de Saúde (SUS) com consultas médicas e internações no mesmo período foi de 2,141 bilhões de reais. Britto et al. (2012) e Lemos et al. (2017) complementam que anualmente no Brasil são registradas cerca de 15 mil mortes e 350 mil internações associadas à precariedade das condições sanitárias.

A Figura 2c ilustra que os municípios com índices de cobertura dos serviços de coleta de resíduos sólidos entre $90,0 \%$ e 100,0\% são Campos Verdes, Britânia, Aragarças, Americano do Brasil, Doverlândia, Nerópolis, Abadia de Goiás, Padre Bernardo, Pires do Rio, Nova Aurora, Três Ranchos e Paranaiguara, enquanto nos demais os índices ficaram entre $60 \%$ e $80 \%$. Uma das possíveis explicações para esse desempenho positivo pode ser o fato de diversos municípios - como Aurilândia, Jandaia, Nerópolis, Piracanjuba, Porangatu, Santa Isabel, Taquaral de Goiás e Vila Propício - integrarem consórcios de gestão compartilhada de resíduos sólidos, modelo político-gerencial associativo que tende a potencializar benefícios socioambientais com redução de custos (CAMPOS, 2013; JABBOUR et al., 2014; LIMA; TORRES; OLIVEIRA FILHO, 2017). Nacionalmente, o índice de coleta é de 91,0\% (SNIS, 2017), entretanto, a destinação final ambientalmente adequada dos resíduos ainda não está no mesmo patamar, desencadeando significativos impactos ambientais e à saúde pública, como poluição e degradação do solo e das coleções hídricas superficiais e subterrâneas, favorecimento da proliferação de vetores de importância sanitária, intensificação de enchentes devido ao assoreamento de rios e córregos e elevação do risco de dispersão de doenças de veiculação hídrica (KLEIN; GONÇALVES-DIAS; JAYO, 2018).

Em relação à drenagem de águas pluviais, a ausência de indicadores oficiais por parte do sistema de informações nacional é preocupante, pois demonstra que o serviço ainda é negligenciado pelo poder público. Nesse sentido, Agostinho e Poleto (2012) e Silva e Hora (2013) destacam que essa vertente do saneamento básico tem papel fundamental no que se refere à manutenção do meio ambiente e da qualidade de vida social, devendo seu planejamento estratégico ser desenvolvido em consonância com o gerenciamento integrado de bacias hidrográficas. Adicionalmente, ao analisarem o déficit nacional em drenagem urbana, Souza; Moraes; Borja (2012) demonstraram a necessidade de ampliação da discussão pública para incorporação de aspectos mais associados a esse serviço, como o déficit de informações especializadas; questões de ordem qualitativa (em relação à sua interferência com outros componentes do saneamento) e técnico-institucionais (no que se refere à ainda predominante fragilidade gerencial das instituições públicas em relação aos aspectos de drenagem e manejo de águas pluviais); de cobertura da rede e da concepção da drenagem, que tende a se limitar ao uso majoritário de técnicas resolutivas tradicionais.

Os resultados referentes aos prestadores dos serviços de saneamento básico obtidos com a aplicação dos questionários são apresentados no Quadro 1, onde se verifica que o abastecimento de água é realizado pela concessionária estadual (Saneamento de Goiás S.A. - SANEAGO) em 52 (94,5\%) deles, à exceção de Cachoeira de Goiás e Vicentinópolis, onde o serviço não é oferecido, e de Paranaiguara, onde é terceirizado. Em relação à coleta de esgoto, a SANEAGO também responde por 15 (27,3\%) municípios, enquanto que em Paranaiguara (1,8\%) é terceirizado e nos outros $39(70,9 \%)$ não é oferecido, cabendo a cada família dar destinação final aos efluentes gerados, o que costuma ocorrer por intermédio de fossas negras, solução ambientalmente inadequada (SIQUEIRA et al., 2017; PAIVA e SOUZA, 2018). No que se refere à coleta de resíduos sólidos, em Montividiu, Nerópolis, Niquelândia, Padre Bernardo e Porangatu o serviço é terceirizado, enquanto que nos outros 50 municípios $(90,9 \%)$ é executado diretamente pelas Prefeituras, por intermédio de Autarquias, Secretarias ou Departamentos. Em termos de drenagem de águas pluviais, na integralidade dos municípios pesquisados o serviço também é realizado pelas Prefeituras, entretanto, quase que exclusivamente de forma emergencial, e não preventiva.

Alguns dos entrevistados afirmaram que empresas terceirizadas ou mesmo a SANEAGO, que já responde pelo fornecimento da água para fins de abastecimento na maior parte dos municípios pesquisados e possui corpo técnico e infraestrutura especializada, poderiam atuar de forma mais intensa em relação aos demais serviços de saneamento, potencializando o atendimento aos contribuintes. Para Silvestre (2012), o

$\begin{array}{llllll}\text { Caminhos de Geografia } & \text { Uberlândia-MG } & \text { v. 23, n. } 85 & \text { fev./2022 } & \text { p. 69-87 } & \text { Página } 74\end{array}$


fato de Prefeituras responderem por demandas dessa natureza tende a resultar em medidas de gerenciamento ineficientes, dadas as limitações de ordem político-administrativa, econômico-financeira, estrutural e operacional (falta de pessoal especializado), realidade ainda comum em grande parte dos municípios brasileiros. Pinheiro; Savoia; Ângelo (2016) destacam que parte da menor eficiência do gerenciamento público em relação ao setor de saneamento normalmente decorre de restrições emanadas das normas regulatórias impostas aos administradores, ou da inexistência de uma estrutura de incentivos que induza o alcance de metas mais elevadas. Adicionalmente, na esfera pública a governança se torna mais complexa devido a variáveis políticas.

Quadro 1 - Estado de Goiás: Identificação dos prestadores dos serviços de saneamento no âmbito dos 55 municípios contemplados no estudo, 2019.

\begin{tabular}{|c|c|c|c|c|c|c|c|c|c|}
\hline \multirow{2}{*}{ MUNICÍPIO } & \multicolumn{4}{|c|}{$\begin{array}{l}\text { SERVICCOS DE } \\
\text { SANEAMENTO }\end{array}$} & \multirow{2}{*}{ MUNICÍPIO } & \multicolumn{4}{|c|}{$\begin{array}{l}\text { SERVICCOS DE } \\
\text { SANEAMENTO }\end{array}$} \\
\hline & AA & ES & RS & DP & & AA & ES & RS & DP \\
\hline (1) Abadia de Goiás & SA & SA & PR & PR & (29) Montividiu do Norte & SA & NO & PR & PR \\
\hline (2) Água Fria de Goiás & SA & NO & PR & PR & (30) Montividiu & SA & SA & TE & PR \\
\hline (3) Americano do Brasil & SA & NO & PR & PR & (31) Mutunópolis & SA & NO & PR & PR \\
\hline (4) Amorinópolis & SA & $\mathrm{NO}$ & PR & PR & (32) Nerópolis & SA & NO & TE & PR \\
\hline (5) Araçu & SA & $\mathrm{NO}$ & PR & PR & (33) Niquelândia & SA & SA & TE & PR \\
\hline (6) Aragarças & SA & $\mathrm{NO}$ & PR & PR & (34) Nova Aurora & SA & SA & PR & PR \\
\hline (7) Arenópolis & SA & NO & PR & PR & (35) Nova Iguaçu de Goiás & SA & NO & PR & PR \\
\hline (8) Aurilândia & SA & $\mathrm{NO}$ & PR & PR & (36) Nova Veneza & SA & NO & PR & PR \\
\hline (9) Bom Jardim de Goiás & SA & NO & PR & PR & (37) Ouro Verde de Goiás & SA & NO & PR & PR \\
\hline (10) Brazabrantes & SA & SA & PR & PR & (38) Padre Bernardo & SA & SA & TE & PR \\
\hline (11) Britânia & SA & SA & PR & PR & (39) Palmelo & SA & NO & PR & PR \\
\hline (12) Cachoeira de Goiás & $\mathrm{NO}$ & NO & PR & PR & (40) Paranaiguara & TE & $\mathrm{TE}$ & PR & PR \\
\hline (13) Campos Verdes & SA & $\mathrm{NO}$ & PR & PR & (41) Piracanjuba & SA & SA & PR & PR \\
\hline (14) Cumari & SA & $\mathrm{NO}$ & $\mathrm{PR}$ & PR & (42) Pires do Rio & SA & SA & PR & PR \\
\hline (15) Damolândia & SA & $\mathrm{NO}$ & PR & PR & (43) Porangatu & SA & SA & TE & $\mathrm{PR}$ \\
\hline (16) Doverlândia & SA & NO & PR & PR & (44) Professor Jamil & SA & NO & PR & PR \\
\hline (!7) Flores de Goiás & SA & NO & PR & PR & (45) Quirinópolis & SA & SA & PR & PR \\
\hline (18) Formoso & SA & NO & PR & PR & (46) Santa Bárbara & SA & NO & PR & PR \\
\hline (19) Goiás & SA & SA & PR & PR & (47) Santa Isabel & SA & NO & PR & PR \\
\hline (20) Gouverlândia & SA & SA & PR & PR & (48) Santa Rosa de Goiás & SA & NO & PR & PR \\
\hline (21) Hidrolina & SA & NO & PR & PR & (49) St. Tereza de Goiás & SA & NO & PR & PR \\
\hline (22) Ivolândia & SA & $\mathrm{NO}$ & PR & PR & (50) Taquaral de Goiás & SA & NO & PR & $\mathrm{PR}$ \\
\hline (23) Jandaia & SA & NO & PR & PR & (51) Teresina de Goiás & SA & NO & PR & PR \\
\hline (24) Jaraguá & SA & SA & PR & PR & (52) Três Ranchos & SA & NO & PR & PR \\
\hline (25) Jaupaci & SA & NO & PR & PR & (53) Vianópolis & SA & NO & PR & PR \\
\hline (26) Mairipotaba & SA & $\mathrm{NO}$ & PR & PR & (54) Vicentinópolis & $\mathrm{NO}$ & $\mathrm{NO}$ & PR & PR \\
\hline (27) Marzagão & SA & $\mathrm{NO}$ & PR & PR & (55) Vila Propício & SA & SA & PR & PR \\
\hline (28) Moiporá & SA & $\mathrm{NO}$ & PR & PR & - & - & - & - & - \\
\hline
\end{tabular}

Legenda - AA - abastecimento de água; ES - esgotamento sanitário; RS - manejo de resíduos sólidos; DP - drenagem pluvial; SA - serviços prestados pela SANEAGO; PR - serviços prestados pelas Prefeituras; TE - serviços prestados por empresas terceirizadas; NO - serviços não oferecidos.

Fonte - Elaborada pelos autores.

p. 69-87 Página 75 
Nesse contexto, Guasch; Laffont; Straub (2008) esclarecem que a partir dos anos 80, países da América Latina e Caribe começaram a transferir a prestação de serviços públicos à iniciativa privada, decorrente da necessidade de realização de investimentos vultosos em infraestrutura, da escassez de recursos públicos e do pressuposto de maior eficiência. Contudo, ainda não existe consenso sobre a melhor maneira de se alcançar excelência na prestação dos serviços de saneamento básico: se mediante parcerias públicoprivadas, concessões, privatizações ou prestação direta por parte do poder público. Naturalmente, isso ocorre devido às diferenças legais, práticas e institucionais que levam a resultados diferentes entre os países. No caso específico do Brasil, atualmente a questão esbarra nos recentes desdobramentos do novo Marco Regulatório do Saneamento (BRASIL, 2020), ainda em discussão. Todavia, independente no mecanismo escolhido, a prestação deve ter eficiência e qualidade (PINHEIRO; SAVOIA; ÂNGELO, 2016).

Em relação à existência de Políticas Municipais de Saneamento Básico, a Figura 3 demonstra que apenas quatro municípios $(7,3 \%)$ - Abadia de Goiás, Paranaiguara, Santa Tereza de Goiás e Vianópolis - a possuem, enquanto que em $23(41,8 \%)$ estão em processo de elaboração e em $28(50,9 \%)$ as discussões não prosseguiram. Em relação aos PMSB, nos 55 municípios (100,0\%) esses estudos ainda estão em processo de elaboração.

Apesar da Política e do Plano Municipal de Saneamento Básico serem os pilares basilares da gestão e da prestação dos serviços sanitários no âmbito local (BRASIL, 2007; CARVALHO e ADAS, 2012; PEREIRA e HELLER, 2015; FUNASA, 2018), o percentual de municípios goianos pesquisados no presente estudo ainda desprovidos desses documentos políticos-gerenciais é elevado, comprovando o atraso do setor no âmbito local. Para Teixeira et al. (2014), essa também é a realidade de grande parte do Brasil e se deve à herança de sucessivas políticas públicas onde os municípios se viram à margem do acesso aos recursos para fins de investimento no setor, às suas dificuldades para conseguirem compor quadros técnicos especializados e a desencontros de ordem político-gerencial.

Figura 3 - Estado de Goiás: Situação dos municípios goianos pesquisados em relação à existência de políticas locais de saneamento básico, 2019.

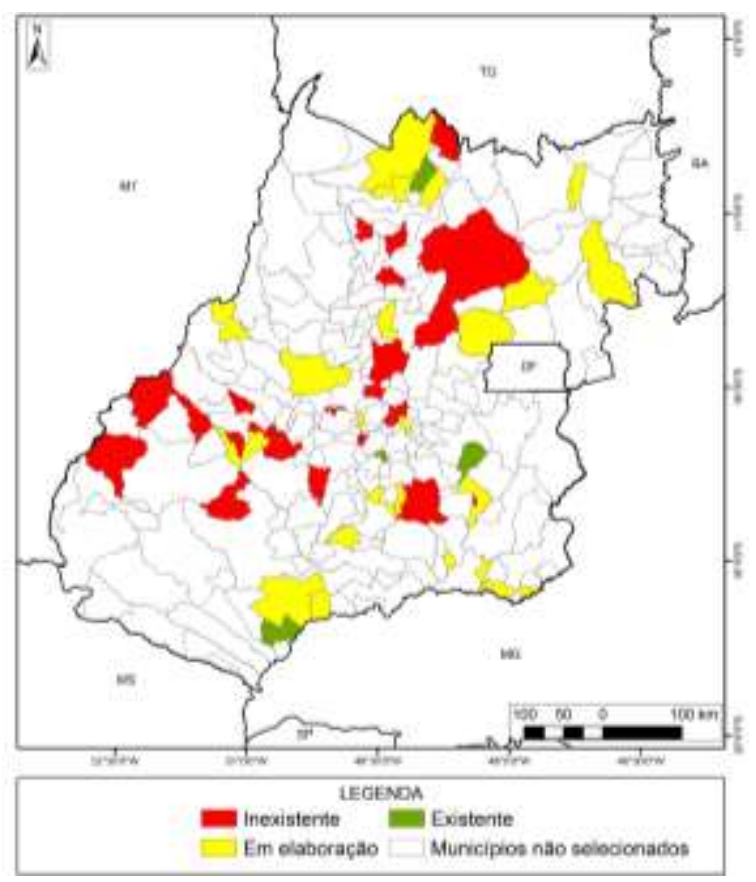

Fonte - Elaborada pelos autores.

Silveira; Heller; Rezende (2013), FUNASA (2014) e Sousa; Sousa; Álvares (2015) esclarecem que enquanto a PoMSB define objetivamente os direitos e deveres dos cidadãos em relação ao saneamento básico, o PMSB deve estabelecer os objetivos, diretrizes, metas e condições de prestação dos serviços para fins de planejamento, detalhando aspectos associados aos planos de investimentos, projetos, prestadores e de atuação da entidade reguladora e fiscalizadora (GALVÃO JÚNIOR; SOBRINHO; SILVA, 2012; LIMA NETO e SANTOS, 2012). Lisboa; Heller; Silveira (2013) esclarecem que o sucesso do efetivo planejamento do setor no âmbito municipal está diretamente associado ao fato da sociedade interessada

$\begin{array}{llllll}\text { Caminhos de Geografia } & \text { Uberlândia-MG } & \text { v. 23, n. } 85 & \text { fev./2022 } & \text { p.69-87 } & \text { Página } 76\end{array}$


conseguir conhecer as reais necessidades sanitárias locais, o que pode ser alcançado mediante o aumento do envolvimento e da participação social, de avanços na gestão e de melhorias na qualidade dos serviços prestados. Para Pereira e Heller (2015) e FUNASA (2018), a participação da sociedade na construção e nas decisões sobre as ações e prioridades definidas na Política e no Plano Municipal de Saneamento Básico é fundamental, sob o risco das necessidades sociais não serem efetivamente atendidas.

$\mathrm{Na}$ Tabela 1 são listados os demais aspectos levantados na pesquisa. Constatou-se que 30 municípios (54,5\%) participam de consórcios voltados para a oferta associada de serviços de saneamento básico, contudo, majoritariamente na área de resíduos sólidos (Quadro 2), indicando a possibilidade de expansão de iniciativas dessa natureza também para os demais componentes do setor. De acordo com Brasil (2005), Brasil (2010) e FUNASA (2014), consórcios são autarquias que integram a administração pública indireta, formados pela união entre dois ou mais entes públicos com o objetivo de desenvolvimento de ações conjuntas que visem benefícios comuns às populações envolvidas, se constituindo em alternativa interessante para muitos municípios de pequeno porte devido ao fato de normalmente ser uma solução menos onerosa. Para Soares (2014), consórcios no setor de saneamento básico tendem a ser mais eficientes e preparados para enfrentar os desafios de uma política pública que apresenta elevada complexidade de implementação.

Tabela 1 - Estado de Goiás: Proporção dos 55 municípios goianos em relação aos demais aspectos políticosgerenciais dos serviços de saneamento básico pesquisados, 2019.

\section{ASPECTO POLÍTICO-GERENCIAL}

\section{NÚMERO DE MUNICÍPIOS ONDE O \\ ASPECTO AVALIADO FOI COMPROVADO}

(un.)

Consórcio de Saneamento Básico

$30(54,5 \%)$

$10(20,0 \%)$

$7(12,7 \%)$

$5(9,1 \%)$

$3(5,4 \%)$

0

0
Conselho de Saneamento Básico

Programas de Saneamento Básico

Fundo Municipal de Saneamento Básico

Ações de educação sanitária

Procedimentos de avaliação dos serviços de saneamento básico

Sistema municipal de informação
IDENTIFICAÇÃO DOS MUNICÍPIOS
$1,2,3,4,5,7,8,10,12$ $13,14,15,17,23,26,29$, $31,32,35,36,38,41,43$, $44,46,47,49,50,53,55$

$8,11,12,17,22,24,25$, $33,43,53$

$1,20,23,32,33,41,42$

$8,24,35,51,53$

$3,19,41$

Fonte - Elaborada pelos autores.

Em regiões integradas por municípios com interesses comuns, a modalidade administrativa de consórcios pode trazer diversos benefícios, favorecendo o ganho de escala mediante a edificação e uso compartilhado de obras como estações de tratamento de água (ETAs) e de efluentes (ETÉs), aterros sanitários, laboratórios, oficinas e estações de transbordo e reciclagem, além de ter como vantagem a racionalização, a otimização da aplicação de recursos públicos e a melhoria da capacidade técnica, gerencial e financeira dos entes associados. Adicionalmente, podem ocorrer atividades de capacitação técnica voltadas ao desenvolvimento de programas coletivos de redução de perdas nos sistemas de abastecimento de água e de desenvolvimento da coleta seletiva; assessoria jurídica e elaboração de projetos e propostas para solicitação de recursos junto aos órgãos de fomento (SOARES, 2014). Todavia, em seu levantamento sobre instrumentos metodológicos para estimular a formação de consórcios públicos voltados para a gestão integrada dos serviços de saneamento, FUNASA (2018) destaca que a cooperação intermunicipal na gestão do setor é uma tendência que não depende exclusivamente do voluntarismo dos municípios, mas do estímulo pelas esferas governamentais Estaduais e Federal, como já ocorre no Brasil com a Política Nacional de Resíduos Sólidos (BRASIL, 2010). Adicionalmente, os mesmos autores destacam que a maior parte dos consórcios existentes no Brasil ainda atua efetivamente apenas em determinados setores e funções específicas do saneamento básico - como identificado no presente estudo -, existindo diversas possibilidades de ampliação da atuação conjunta, sendo que o sucesso das experiências de governança compartilhada dos serviços públicos no âmbito local não depende apenas dos desenhos dos consórcios propriamente ditos, mas da qualidade dos processos de

$\begin{array}{lllll}\text { Caminhos de Geografia } & \text { Uberlândia-MG } & \text { v. 23, n. } 85 & \text { fev./2022 } & \text { p. 69-87 Página } 77\end{array}$


coordenação entre as instituições envolvidas, aspectos que devem caminhar conjuntamente sempre visando à melhoria da qualidade de vida das populações atendidas.

Os resultados apresentados na Tabela 1 também demonstram que em relação aos Conselhos de Saneamento Básico, apenas dez municípios $(18,2 \%)$ informaram possuir essa figura de controle social legalmente instituída e em funcionamento, como Vianópolis, onde o Conselho foi instituído pela Lei Municipal $\mathrm{n}^{\circ}$ 1.137, de 28 de abril de 2017, e conta com representantes dos titulares e prestadores dos serviços, órgãos governamentais, usuários, entidades técnicas e de organizações da sociedade civil e de defesa do consumidor relacionadas ao setor.

Quadro 2 - Estado de Goiás: Consórcios de Saneamento Básico identificados no estudo. Estão listados apenas os diretamente associados ao setor, ainda que na forma apenas de protocolo de intenções, 2019.

\begin{tabular}{|c|c|}
\hline MUNICÍPIO & CONSÓRCIO \\
\hline (1) Abadia de Goiás & - Resíduos sólidos: Consórcio Vale do Rio dos Bois. \\
\hline (2) Água Fria de Goiás & $\begin{array}{l}\text { - Consórcio Público de Manejo dos Resíduos Sólidos e das Águas Pluviais da } \\
\text { Região Integrada do Distrito Federal e Goiás, e o Consórcio Intermunicipal dos } \\
\text { Usuários de Recursos Hídricos para Gestão Ambiental da Bacia Hidrográfica do } \\
\text { Alto Tocantins }\end{array}$ \\
\hline (3) Americano do Brasil & $\begin{array}{l}\text { - Resíduos sólidos: Consórcio Intermunicipal de Desenvolvimento de Gestão } \\
\text { Associada de Serviços Públicos. }\end{array}$ \\
\hline (4) Amorinópolis & $\begin{array}{l}\text { - Resíduos sólidos: Protocolo de intenções visando à constituição do Consórcio } \\
\text { Intermunicipal de Municípios da Microrregião do Araguaia. }\end{array}$ \\
\hline (5) Araçu & - Resíduos sólidos: Consórcio Intermunicipal Brasil Central. \\
\hline (7) Arenópolis & $\begin{array}{l}\text { - Saneamento: Consórcio Público } \\
\text { Desenvolvimento do Estado de Goiás. }\end{array}$ \\
\hline (8) Aurilândia & $\begin{array}{l}\text { - Resíduos sólidos: Consórcio Intermunicipal de Saúde da Região Oeste II } \\
\text { (resíduos de serviços de saúde), e o Consórcio Intermunicipal Brasil Central. }\end{array}$ \\
\hline (10) Brazabrantes & $\begin{array}{l}\text { - Consórcio Público de Manejo de Resíduos Sólidos e de Águas Pluviais da } \\
\text { Região da Associação dos Municípios do Alto Meia Ponte e Adjacentes, Região } \\
\text { Metropolitana de Goiânia e Municípios Adjacentes à Grande Goiânia. }\end{array}$ \\
\hline (12) Cachoeira de Goiás & - Consórcio Intermunicipal de Gestão Integrada de Resíduos Sólidos. \\
\hline (13) Campos Verdes & $\begin{array}{l}\text { - Consórcio Público Intermunicipal de Manejo dos Resíduos Sólidos e das } \\
\text { Águas Pluviais da Região do Vale do São Patrício - Goiás. }\end{array}$ \\
\hline (14) Cumari & - Resíduos sólidos: Consórcio Intermunicipal do Sudeste Goiano. \\
\hline (15) Damolândia & - Resíduos sólidos: Consórcio Intermunicipal Brasil Central. \\
\hline (!7) Flores de Goiás & $\begin{array}{l}\text { - Resíduos sólidos e esgoto: Consórcio Intermunicipal de Saneamento Básico e } \\
\text { Ambiental do Nordeste Goiano. }\end{array}$ \\
\hline (23) Jandaia & - Resíduos sólidos: Consórcio Intermunicipal de Desenvolvimento Sustentável. \\
\hline (26) Mairipotaba & $\begin{array}{l}\text { - Saneamento: Consórcio Intermunicipal de Desenvolvimento Regional Três } \\
\text { Rios. }\end{array}$ \\
\hline (29) Montividiu do Norte & - Saneamento: Consórcio Intermunicipal Vale do Santa Tereza. \\
\hline (31) Mutunópolis & - Saneamento: Consórcio de Desenvolvimento da Região Norte de Goiás. \\
\hline (32) Nerópolis & $\begin{array}{l}\text { - Consórcio Público de Manejo de Resíduos Sólidos e de Águas Pluviais da } \\
\text { Região da Associação dos Municípios do Alto Meia Ponte e Adjacentes, Região } \\
\text { Metropolitana de Goiânia e Municípios Adjacentes à Grande Goiânia. }\end{array}$ \\
\hline (35) Nova Iguaçu de Goiás & - Resíduos sólidos: Consórcio de Administração Rio dos Bois Região Norte. \\
\hline (36) Nova Veneza & $\begin{array}{l}\text { - Consórcio Público de Manejo de Resíduos Sólidos e de Águas Pluviais da } \\
\text { Região da Associação dos Municípios do Alto Meia Ponte e Adjacentes, Região } \\
\text { Metropolitana de Goiânia e Municípios Adjacentes à Grande Goiânia. }\end{array}$ \\
\hline (38) Padre Bernardo & $\begin{array}{l}\text { - Protocolo de intenção de participação do Consórcio Público de Manejo dos } \\
\text { Resíduos Sólidos e das Águas Pluviais da Região Integrada do Distrito Federal } \\
\text { e Goiás. }\end{array}$ \\
\hline
\end{tabular}

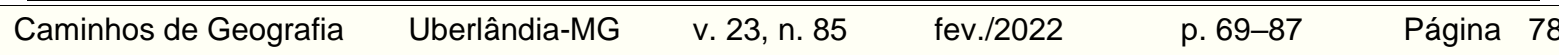




\begin{tabular}{|l|l|}
\hline (41) Piracanjuba & - Resíduos sólidos: Consórcio da Estrada de Ferro - Eixo GO 020. \\
\hline (43) Porangatu & - Resíduos sólidos: Consórcio de Desenvolvimento da Região Norte de Goiás. \\
\hline (44) Professor Jamil & $\begin{array}{l}\text { - Resíduos sólidos: Consórcio Intermunicipal de Desenvolvimento Regional Três } \\
\text { Rios. }\end{array}$ \\
\hline (46) Santa Bárbara & $\begin{array}{l}\text { - Consórcio Público de Manejo de Resíduos Sólidos e de Águas Pluviais da } \\
\text { Região da Associação dos Municípios do Alto Meia Ponte e Adjacentes, Região } \\
\text { Metropolitana de Goiânia e Municípios Adjacentes à Grande Goiânia. }\end{array}$ \\
\hline (47) Santa Isabel & $\begin{array}{l}\text { - Consórcio Público de Manejo dos Resíduos Sólidos e das Águas Pluviais da } \\
\text { Região do Vale do São Patrício. }\end{array}$ \\
\hline (49) Santa Tereza de Goiás & $\begin{array}{l}\text { - Resíduos sólidos: Protocolo de intenções para participação do Consórcio } \\
\text { Intermunicipal Vale do Santa Tereza de Goiás. }\end{array}$ \\
\hline (50) Taquaral de Goiás & $\begin{array}{l}\text { - Consórcio Público de Manejo de Resíduos Sólidos e de Águas Pluviais da } \\
\text { Região da Associação dos Municípios do Alto Meia Ponte e Adjacentes, Região } \\
\text { Metropolitana de Goiânia e Municípios Adjacentes à Grande Goiânia. }\end{array}$ \\
\hline (53) Vianópolis & $\begin{array}{l}\text { - Consórcio Público de Manejo de Resíduos Sólidos e de Águas Pluviais da } \\
\text { Região da Associação dos Municípios do Alto Meia Ponte e Adjacentes, Região } \\
\text { Metropolitana de Goiânia e Municípios Adjacentes à Grande Goiânia. }\end{array}$ \\
\hline (55) Vila Propício & $\begin{array}{l}\text { - Consórcio Público de Manejo dos Resíduos Sólidos e das Águas Pluviais da } \\
\text { Região do Vale do São Patrício-Goiás. }\end{array}$ \\
\hline
\end{tabular}

Fonte - Elaborada pelos autores.

As principais competências do Conselho de Saneamento Básico de Vianópolis são atuar de forma consultiva e deliberativa, propondo diretrizes para a PoMSB e o PMSB quanto à sua formulação, planejamento e avaliação; acompanhar e assessorar o poder executivo nos processos de elaboração, atualização e revisão da PoMSB e do PMSB e deliberar acerca da aplicação de recursos oriundos do Fundo Municipal de Saneamento Básico. Em praticamente todos os outros 45 municípios pesquisados $(81,8 \%)$, o tema acaba sendo discutido, ainda que indiretamente, em outras esferas de controle social (Conselhos de Meio Ambiente ou de Saúde), como no município de Goiás.

De acordo com Gohn (2004) e Nunes; Phillippi Junior; Fernandes (2012), conselhos são sistemas de controle social que combinam conceitos da democracia direta, representando e agregando mecanismos de representação política onde os indivíduos se comportam como cidadãos políticos ativos, aptos a atingirem consenso durante os processos de participação e elaboração das políticas públicas voltadas para cada setor. Especificamente, Conselhos de Saneamento Básico se constituem em instâncias colegiadas de caráter deliberativo e consultivo que passaram a ser obrigatórias nos municípios brasileiros apenas a partir de 2014, quando foi regulamentada a Lei no 11.445/2007 (BRASIL, 2007). Antes disso, eram considerados temáticos, instituídos mediante a iniciativa autônoma dos gestores municipais (MELLO e REZENDE, 2014). Nesse sentido, FUNASA (2018) e Souza e Heller (2019) destacam que Conselhos de Saneamento Básico são mecanismos de controle social fundamentais e indispensáveis à prestação eficiente dos serviços, pois garantem à sociedade informações, representações técnicas e participação nos processos de formulação de políticas, planejamento e avaliação relacionados ao setor. Contudo, a participação popular nessas instâncias não deve se limitar a simples consultas e debates em audiências públicas, que por si só não possibilitam a promoção da cidadania ativa (GALVÃO JÚNIOR; BRANCO SOBRINHO; SILVA, 2012; LIMA NETO e SANTOŞ, 2012; SOUZA, 2016). Ao contrário, a atuação social necessita ser contínua e suficientemente profunda em termos de envolvimento com a gestão política do saneamento básico na municipalidade, visando avanços reais dos serviços (PITERMAN; HELLER; REZENDE, 2013). Outro aspecto não menos importante é que essas instâncias devem apresentar funcionamento regular, capacidade para atuar nas decisões tomadas pelo município e ampla participação popular.

Especificamente, o controle social está previsto como um dos princípios fundamentais da prestação dos serviços públicos de saneamento básico, ao lado de outros como universalização de acesso, integralidade, disponibilidade, eficiência e sustentabilidade econômica (BRASIL, 2007). Todavia, o desenvolvimento da noção de controle social na população brasileira é uma empreitada desafiadora, mesmo em cidades com conselhos estabelecidos há mais tempo. De acordo com Piterman; Heller; Rezende (2013), a avaliação sobre a ausência/precariedade do controle social em relação ao setor de saneamento básico é imprescindível, dadas as fragilidades estruturais e organizacionais ainda predominantes no país, se configurando em um laboratório para o exercício de atuação coletiva da cidadania. Adicionalmente, existe o agravante de que municípios que não instituírem o controle social por intermédio de legislação específica não poderão ter acesso a recursos governamentais destinados ao setor.

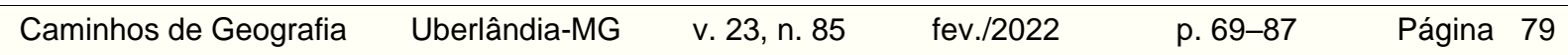


Para Cunha e Borja (2018), a simples formulação de programas que deem coerência à governança dos serviços de saneamento não é condição suficiente de sucesso, pois a dinâmica operacional de sua implementação pode e usualmente consegue subverter a lógica do planejamento. Por outro lado, essa condição não deve ser impedimento para a formulação de iniciativas consistentes, articuladas e com estruturas que induzam a um alinhamento ao planejamento, pois a existência de programas específicos é indispensável para a concretização de avanços ligados ao setor de saneamento básico, notadamente no sentido de assegurar a melhoria da gestão e da prestação dos serviços (FUNASA, 2014). No caso específico do presente estudo, é fundamental que os gestores públicos dos municípios pesquisados empreendam esforços para a criação e implementação de mais programas sanitários, principalmente em áreas ocupadas por populações de baixa renda, o que poderá ser realizado com o auxílio de ações já em execução por parte do Governo Federal, como os Programas Nacionais de Resíduos Sólidos Urbanos, de Águas Subterrâneas, de Educação Ambiental e Mobilização Social em Saneamento, Produtor de Água, de Revitalização de Bacias Hidrográficas em Situação de Vulnerabilidade e Degradação Ambiental, Serviços Urbanos de Água e Esgoto e de Saneamento Rural), e por parte do estado de Goiás, como o Projeto Caixa D’Água Legal, Módulos Sanitários Domiciliares, Olho no Óleo e Sanear Goiás.

Em relação aos Fundos de Saneamento Básico (Tabela 1), que representam fontes regulares de recursos para o financiamento parcial ou total de ações, projetos e programas voltados para a universalização dos serviços, apenas cinco dos municípios goianos pesquisados $(9,1 \%)$ comprovaram possuir o instrumento instituído: Aurilândia, Jaraguá, Nova Iguaçu, Teresina de Goiás e Vianópolis. Segundo FUNASA (2014), fundos dessa natureza podem ser constituídos de dotações orçamentárias do município, de outros níveis de Governo e de outros fundos, bem como de doações e subvenções nacionais e internacionais, servindo até mesmo para garantia em operações de crédito para financiamento dos investimentos necessários à implementação dos serviços (BRASIL, 2007), desde que estejam em conformidade com as diretrizes dos Planos Municipais de Saneamento Básico. De acordo com Mello e Rezende (2014) e Pereira e Heller (2015), sua gestão necessita ficar a cargo de um grupo dotado de competências para a definição das diretrizes e dos mecanismos de acompanhamento, fiscalização e controle, como o Conselho de Saneamento Básico, que deve definir as diretrizes e mecanismos de acompanhamento, fiscalização e controle dos recursos. Se adequadamente administrados e submetidos a um rígido controle social, e não se sujeitando a ingerências de cunho político, os Fundos de Saneamento Básico assumem importância fundamental na consolidação dos serviços, pois garantem que recursos financeiros cheguem ao âmbito local de maneira efetiva. Considerando que a previsão de investimentos no setor de saneamento nos países que integram os BRICS (Brasil, Rússia, Índia, China e África do Sul) até 2025 deverão ser da ordem de 576 bilhões de dólares (OCDE, 2011), a constituição de Fundos Municipais de Saneamento assume caráter de urgência para fins de obtenção de recursos para o setor nos municípios goianos pesquisados.

Ainda de acordo com os resultados apresentados na Tabela 1, apenas os municípios de Americano do Brasil, Piracanjuba e Goiás (5,4\%) conseguiram comprovar atuação em educação sanitária. Este último se destaca por contar com duas iniciativas educativas relevantes ligadas ao setor, ainda que indiretamente: 0 Projeto Ser Natureza e o Festival Internacional de Cinema e Vídeo Ambiental (FICA). O primeiro, realizado em parceria com o Ministério Público do Estado de Goiás (MP-GO), tem desenvolvido ações voltadas para a recuperação de nascentes e a proteção de mananciais de abastecimento público, enquanto o FICA (em sua $21^{\underline{a}}$ edição) vem fomentando ações locais voltadas para o saneamento, como o Projeto FICA Limpo, iniciativa que busca tornar o festival mais sustentável. Segundo FUNSASA (2014), a educação é indispensável para que um município avance em relação aos serviços de saneamento, pois busca modificar comportamentos inadequados dos usuários dos sistemas, como a disposição equivocada de resíduos sólidos destinados à coleta seletiva, o uso irracional da água de abastecimento, o descarte incorreto de produtos químicos capazes de afetar a rede de coleta ou o sistema de tratamento de efluentes e o uso inadequado dos sistemas de drenagem pluvial. Para os mesmos autores, o saneamento deve envolver um profundo processo educativo da população, sendo necessária a construção da percepção de que os serviços de saneamento básico são um bem coletivo e indispensável à manutenção da qualidade de vida humana e ambiental (MEDEIROS et al., 2011; GAMA, 2017).

No que se refere aos procedimentos de avaliação dos serviços de saneamento e aos sistemas de informação (Tabela 1), nenhum dos 55 municípios pesquisados comprovou sua existência. Em termos avaliativos, é fundamental que a eficácia, a eficiência e a efetividade do setor sejam constantemente analisadas, de forma a contribuir para a efetivação de aspectos como regularidade, continuidade, segurança no controle de riscos aos usuários, atualidade das técnicas empregadas, cortesia dos colaboradores para com os usuários, universalidade do direito ao atendimento, sustentabilidade econômica e melhoria dos níveis de saúde da população (BRASIL, 2007; FUNASA, 2018). Contudo, até o

$\begin{array}{llllll}\text { Caminhos de Geografia } & \text { Uberlândia-MG } & \text { v. 23, n. } 85 & \text { fev./2022 } & \text { p. } 69-87 & \text { Página } 81\end{array}$


momento a quase integralidade dos municípios brasileiros ainda desconhece critérios claros para avaliações dessa natureza, que, na prática, acaba sendo realizada, quando o é, de forma não sistematizada. Consequentemente, os avanços no oferecimento dos serviços não ocorrem ou acontecem em intervalos maiores que o desejado, resultando em atrasos temporais que poderiam ser mitigados mediante procedimentos de monitoramento satisfatórios. De acordo com Scaratti; Michelon; Scaratti (2013), para que os gestores consigam acompanhar a qualidade dos serviços sanitários prestados em seus respectivos municípios, o estabelecimento de indicadores de desempenho que possam ser utilizados em monitoramentos sistemáticos, promovendo a identificação de possíveis anomalias e inconformidades, é indispensável. Para tanto, podem ser utilizados índices baseados em aspectos como, por exemplo, disponibilidade e regularidade no fornecimento de água, hidrometração, desempenho financeiro do sistema de abastecimento, perdas de faturamento e na distribuição, atendimento total e fluoretação, para águas de abastecimento; coleta e tratamento de esgoto e consumo de energia elétrica, para sistemas de esgotamento sanitário; quantidade de resíduos coletados pelo agente público e população urbana atendida pela coleta de lixo, para resíduos sólidos; e atendimento com sistema de drenagem, vias urbanas dotadas de galeria de águas pluviais e sujeitas a alagamentos, para drenagem pluvial.

Não menos importantes, os sistemas de informações de saneamento básico se constituem em ferramentas elementares para auxiliar os municípios na gestão dos serviços, devendo subsidiar a tarefa governamental e o controle social no acompanhamento e na avaliação dos resultados dos Planos Municipais de Saneamento Básico (LISBOA; HELLER; SILVEIRA, 2013; FUNASA, 2018). No caso dos municípios onde a SANEAGO e empresas terceirizadas atuam como prestadoras, o gerenciamento de dados é interno, contudo, as informações não são disponibilizadas de maneira efetiva e satisfatória para a população, o mesmo ocorrendo quando os serviços são realizados pelas Prefeituras. Alguns canais de comunicação existem, como sites e telefones, mas basicamente para o relato de situações emergenciais. Nesse sentido, segundo Condurú e Pereira (2017), sistemas com esse enfoque ainda são poucos e ineficientes em praticamente todo o país. Em seu estudo sobre a implantação e o fortalecimento de sistemas de informações nos municípios paraenses, estes mesmos autores constataram a falta de registros sistemáticos, de integração, de compartilhamento e de disponibilização das informações produzidas, tendo comprovado a deficiência do ciclo de comunicação e informação do setor. Ao final do estudo, concluíram que a implantação de sistemas de informações locais como instrumento da Política Estadual de Saneamento Básico do Pará é fundamental para que o conhecimento informacional do setor pela população atendida aumente. Adicionalmente, indicaram a necessidade de elevação da participação dos municípios paraenses na alimentação do Sistema Nacional de Informações sobre Saneamento (SNIS), disponibilizando estatísticas, indicadores e outras informações relevantes, possibilitando, assim, o fácil monitoramento da qualidade dos serviços prestados (PEIXOTO, 2013; NIRAZAWA e OLIVEIRA, 2018).

De forma geral, verifica-se que nenhum dos municípios goianos pesquisados conseguiu comprovar a existência de todos os aspectos de saneamento básico investigados. Mesmo no que se refere às bases políticas e técnicas essenciais para a consolidação do saneamento em seus respectivos territórios, as deficiências se mostram profundas, dada a ainda predominante inexistência de Políticas e Planos Municipais de Saneamento Básico. Consequentemente, as figuras dos consórcios, conselhos e programas de saneamento básico, bem como de ações de educação sanitária e de procedimentos de avaliação e sistemas de informação sobre os serviços também demonstram ser inexistentes ou deficientes. Outro aspecto identificado é o fato de que a participação da sociedade civil no controle social dos serviços não é satisfatória, necessitando avançar (BRASIL, 2007; GOHN, 2004; NUNES; PHILLIPPI JUNIOR; FERNANDES, 2012; MELLO e REZENDE, 2014; FUNASA, 2018; SOUZA e HELLER, 2019). Uma das possíveis explicações para esses atrasos consiste na complexa relação do pacto federativo brasileiro, um país-continente que apresenta desafios consideráveis no que diz respeito à definição clara do papel de cada ente administrativo, tendo em vista o fato das políticas públicas serem historicamente centralizadas na União e nos Estados, resultando na falta de integração entre as diferentes esferas de gestão e dificultando sua implementação por parte dos gestores locais (FUNASA, 2018). Outro aspecto é a diversidade das especificidades políticos-gerenciais de cada município, não contemplada no atual arcabouço legal associado ao setor.

Este cenário demonstra o atraso na implantação da Política Nacional de Saneamento Básico que ainda predomina no horizonte amostral estudado, mesmo após treze anos de promulgação da Lei 11.445/2007 (BRASIL, 2007). Naturalmente, a solução para que se possa garantir o acesso aos serviços de saneamento básico para todos não se resume a questões de viabilidade econômica e técnica, devendo contemplar, em igual escala de importância, a política social. Indubitavelmente, apesar do longo caminho que os 55 municípios goianos estudados ainda precisarão percorrer na busca pela universalização dos

\begin{tabular}{|c|c|}
\hline$C$ & Uberlândia-MG \\
\hline
\end{tabular}


serviços sanitários, as diretrizes já se encontram definidas pela União (BRASIL, 2007) e o estado de Goiás (BRASIL, 2016), cabendo às coletividades locais assumirem efetivamente seus papéis de protagonistas para lograrem mudanças reais no âmbito local. Todavia, não se trata apenas de criar leis e planos e destinar recursos, mas de adotar medidas gerenciais acertadas e de cunho intersetorial, sem favorecimento desta ou daquela camada da população e buscando eliminar prejuízos associados a possíveis disputas políticas. Por outro lado, as administrações públicas locais também precisarão exercer a governança de forma efetiva, executando ações articuladas entre os vários setores que possuem interfaces com o saneamento básico na busca pelo alcance das metas de melhoria dos serviços, estabelecidas no planejamento estratégico municipal e em programas, projetos e ações específicos.

\section{CONSIDERAÇÕES FINAIS}

Após a análise sistemática dos resultados, restou evidenciado todos os municípios pesquisados ainda se encontram atrasados no que diz respeito à universalização do acesso e à integralidade da oferta dos serviços de saneamento, dada a ausência quase generalizada de instrumentos legais, técnicos e políticosgerenciais básicos disciplinadores do tema no âmbito local, como de Políticas e Planos Municipais de Saneamento Básico, consórcios, conselhos, programas, fundos, ações de educação sanitária, procedimentos de avaliação e sistemas de informações do setor.

Nesse sentido, para tornar o saneamento básico realidade em seus respectivos territórios, é necessário que suas populações se apropriem das potencialidades já consolidadas e unam esforços na busca por avanços efetivos e constantes. Nesse sentido, a elaboração da PoMSB e do PMSB inicia o ciclo de organizar ou reestruturar o setor no âmbito local, na perspectiva de uma política pública, de uma ação de Estado. Entretanto, deve-se tomar cuidado para que as ações não se encerrem apenas nesses dois instrumentos, cabendo aos municípios se apropriarem de suas respectivas políticas/planos, assim que devidamente instituídos, a fim de torná-los realidade, entendendo seus fundamentos e pressupostos de forma a concretizar a ampliação do acesso aos serviços de saneamento mediante ações conectadas e contínuas, em plena consonância com as diretrizes advindas da própria comunidade atendida e dos marcos legais instituídos. Para tanto, é indispensável que os serviços sejam prestados com base em práticas consistentes de planejamento, regulação, fiscalização e controle social, de forma a promover a redução das desigualdades e a melhoria da qualidade ambiental e de vida da população.

\section{AGRADECIMENTOS}

Os autores agradecem ao Instituto Federal de Educação, Ciência e Tecnologia de Goiás e à Fundação Nacional de Saúde.

\section{REFERÊNCIAS}

AGOSTINHO, M. S. P.; POLETO, C. Sistemas sustentáveis de drenagem urbana: dispositivos. Revista Holos Environment, v.12, n.2, p.121-131, 2012. https://doi.org/10.14295/holos.v12i2.3054

ANDRADE, L. R. S.; BARBOSA, R. F.; ALEXANDRE, S. N.; FEITOSA, P. H. C. Universalização do serviço de abastecimento de água na percepção do usuário no município de Itapororoca (PB). Revista Ibero-Americana de Ciências Ambientais, v.10, n. 4, p.289-300, 2019. https://doi.org/10.6008/CBPC2179-6858.2019.004.0022

ARAÚJO, S. C.; SILVA FILHO, J. A.; SILVA, G. M. S.; SOBRINHO, L. G. A.; NOGUEIRA, V. F. B. Espacialização dos serviços básicos de saneamento na zona rural do município de Pombal-PB. Revista Verde de Agroecologia e Desenvolvimento Sustentável, v.11, n.3, p.122-130, 2016. https://doi.org/10.18378/rvads.v11i3.4387

BRASIL. Lei no 11.107, de 6 de abril de 2005. Dispõe sobre normas gerais de contratação de consórcios públicos e dá outras providências. Diário Oficial da República Federativa do Brasil, Brasília, DF, 07 abr., 2005.

BRASIL. Lei no 11.445, de 5 de janeiro de 2007. Estabelece diretrizes nacionais para o saneamento básico. Diário Oficial da República Federativa do Brasil, Brasília, DF, 08 jan., 2007.

BRASIL. Lei no 12.305, de 2 de agosto de 2010. Institui a Política Nacional de Resíduos Sólidos. Diário Oficial da República Federativa do Brasil, Brasília, DF, 06 ago., 2010.

$\begin{array}{llllll}\text { Caminhos de Geografia } & \text { Uberlândia-MG } & \text { v. 23, n. } 85 & \text { fev./2022 } & \text { p. } 69-87 & \text { Página } 83\end{array}$


BRASIL. Lei no 19.453, de 16 de setembro de 2016. Institui a Política Estadual de Saneamento Básico de Goiás. Diário Oficial da República Federativa do Brasil, Brasília, DF, 20 set., 2016.

BRASIL. Lei no 14.026, de 15 de julho de 2020. Atualiza o marco legal do saneamento básico. Diário Oficial da República Federativa do Brasil, Brasília, DF, 16 jul., 2020.

BRITTO, A. L. N. P.; LIMA, S. C. R. B.; HELLER, L.; CORDEIRO, B. S. Da fragmentação à articulação: a Política Nacional de Saneamento e seu legado histórico. Revista Brasileira de Estudos Urbanos e Regionais, v.14, n.1, p.65-83, 2012. https://doi.org/10.22296/2317-1529.2012v14n1p65

CAMPOS, H. K. T. Recycling in Brazil: challenges and prospects. Resources, Conservation and Recycling, v.85, p.130-138, 2013. https://doi.org/10.1016/i.resconrec.2013.10.017

CARVALHO, A. O.; ADAS, C. C. Gestão do saneamento básico: abastecimento de água e esgotamento sanitário. Barueri: Manole, 2012.

CONDURÚ, M. T.; PEREIRA, J. A. R. Gestão da informação em saneamento básico no estado do Pará sob o enfoque do ciclo informacional. Revista Engenharia Sanitária e Ambiental, v.22, n.6, p.1225-1232, 2017. https://doi.org/10.1590/s1413-41522017145238

COOPER, D. R.; SCHINDLER, P. S. Métodos de pesquisa em administração. Porto Alegre, RS: Bookman, 2003.

CRISPIM, D. L.; RODRIGUES, R. S. S.; VIEIRA, A. S. A.; SILVEIRA, R. N. C. O.; FERNANDES, L. L. Espacialização da cobertura do serviço de saneamento básico e do índice de desenvolvimento humano dos municípios do Marajó, Pará. Revista Verde de Agroecologia e Desenvolvimento Sustentável, v.11, n.4, p.1-11, 2016. https://doi.org/10.18378/rvads.v11i4.4507

CUNHA, M. A.; BORJA, P. C. O programa de aceleração do crescimento no estado da Bahia e os desafios da universalização do saneamento básico. Revista Brasileira de Gestão Urbana, v.10, n.1, p.173-185, 2018. https://doi.org/10.1590/2175-3369.010.supl1.ao09

EVARISTO, G. V.; CORDEIRO, J.; ALVARENGA, C. A.; OPORTO, L. T.; QUINTÃO, P. L.; CALAZANS, G. M.; CORDEIRO, J. L. Saneamento básico e percepção ambiental: um estudo realizado na comunidade Candidópolis em Itabira, Minas Gerais. Research, Society and Development, v.4, n.1, p.45-61, 2017. https://doi.org/10.17648/rsd-v4i1.28

FUNASA - Fundação Nacional de Saúde. Caderno de Pesquisa em Engenharia de Saúde Pública. Brasília, DF: FUNASA, 2018.

FUNASA - Fundação Nacional de Saúde. Orientações metodológicas para programa de educação ambiental em saneamento para pequenos municípios: caderno de orientações. Brasília: FUNASA, 2014.

GALVÃO JÚNIOR, A. C.; BRANCO SOBRINHO, G.; SILVA, A. C. Painel de Indicadores para Planos de Saneamento Básico. In: PHILIPPI JÚNIOR, A.; GALVÃO JÚNIOR, A. C. (Ed.). Gestão do Saneamento Básico: abastecimento de água e esgotamento sanitário. Barueri: Manole, 2012.

GAMA, A. A. Educação ambiental: abordagens e perspectivas. Revista Científica Multidisciplinar Núcleo do Conhecimento, v.3, p.52-60, 2017.

GIATTI, L. L. Reflexões sobre água de abastecimento e saúde pública: um estudo de caso na Amazônia brasileira. Saúde e Sociedade, v.16, n.1, p.134-144, 2007. https://doi.org/10.1590/S010412902007000100012

GIL, A. C. Métodos e técnicas de pesquisa social. 6. ed. São Paulo: Atlas, 2008.

GOHN, M. G. Os conselhos municipais e a gestão urbana. In: SANTOS JÚNIOR, O. A.; RIBEIRO, L. C. Q.; AZEVEDO, S. (Eds.). Governança democrática e poder local: a experiência dos conselhos municipais no Brasil. Rio de Janeiro: Revan, 2004.

GUASCH, J. L.; LAFFONT, J.; STRAUB, S. Renegotiation of concession contracts in Latin America: evidence from the water and transport sectors. International Journal of Industrial Organization, v.26, n.2, p.421-442, 2008. https://doi.org/10.1016/.ijindorg.2007.05.003

HELLER, L.; NASCIMENTO, N. O. Pesquisa e desenvolvimento na área de saneamento no Brasil: necessidades e tendências. Revista Engenharia Sanitária e Ambiental, v.10, n.1, p.24-35, 2005. https://doi.org/10.1590/S1413-41522005000100004

$\begin{array}{llllll}\text { Caminhos de Geografia } & \text { Uberlândia-MG } & \text { v. 23, n. } 85 & \text { fev./2022 } & \text { p. } 69-87 & \text { Página } 84\end{array}$


IBGE - Instituto Brasileiro de Geografia e Estatística. Série cidades. Brasília: IBGE, 2010.

IBGE - Instituto Brasileiro de Geografia e Estatística. Perfil dos municípios brasileiros: aspectos gerais da gestão de saneamento básico. Brasília: IBGE, 2017.

JABBOUR, A. B. L. S.; JABBOUR, C. J. C.; SARKIS, J.; GOVINDAN, K. Brazil's new national policy on solid waste: challenges and opportunities. Clean Technologies and Environmental Policy, v.16, n.1, p.7-9, 2014. https://doi.org/10.1007/s10098-013-0600-z

KLEIN, F. B.; GONÇALVES-DIAS, S. L. F.; JAYO, M. Gestão de resíduos sólidos urbanos nos municípios da Bacia Hidrográfica do Alto Tietê: uma análise sobre o uso de TIC no acesso à informação governamental. Revista Brasileira de Gestão Urbana, v.10, n.1, p.140-153, 2018. https://doi.org/10.1590/2175-3369.010.001.a010

LEMOS, J. R. L. L.; MATINC, C.; ALMEIDA, W. F.; KONRAD, O. Saneamento básico na região Oeste do Paraná. Revista Ibero-americana de Ciências Ambientais, v.8, n.3, p.151-159, 2017. https://doi.org/10.6008/SPC2179-6858.2017.003.0014

LEONETI, A. B.; PRADO, E. L.; OLIVEIRA, S. V. W. B. Saneamento básico no Brasil: considerações sobre investimentos e sustentabilidade para o século XXI. Revista de Administração Pública, v.45, n.2, p.331-348, 2011. https://doi.org/10.1590/S0034-76122011000200003

LIMA NETO, I. E.; SANTOS, A. B. D. Planos de Saneamento Básico. In: PHILIPPI JÚNIOR, A.; GALVÃO JÚNIOR, A. C. Gestão do Saneamento Básico: abastecimento de água e esgotamento sanitário. Barueri: Manole, 2012.

LIMA, A. G.; TORRES, D. M.; OLIVEIRA FILHO, F. S. Destino final dos resíduos sólidos do Distrito Lagoa da Cruz, municípios de Princesa Isabel (PB) e Quixaba (PE). Revista de Agroecologia no Semiárido, v.1, n.1, p.34-45, 2017. https://doi.org/10.35512/ras.v1i1.1638

LIMA, A. S. C.; ARRUDA, P. N.; SCALIZE, P. S. Indicadores de salubridade ambiental em 21 municípios do estado de Goiás com serviços públicos de saneamento básico operados pelas prefeituras. Revista Engenharia Sanitária Ambiental, v. 24, n.3, p.439-452, 2019. https://doi.org/10.1590/s1413$\underline{41522019188336}$

LIMA, A. S. C.; SCALIZE, P. S.; ARRUDA, P. N.; BAUMANN, L. R. F. Satisfação e percepção dos usuários dos sistemas de saneamento de municípios goianos operados pelas prefeituras. Revista Engenharia Sanitária e Ambiental, v.22, n.3, p.415-428, 2017.

LISBOA, S. S.; HELLER, L.; SILVEIRA, R. B. Desafios do planejamento municipal de saneamento básico em municípios de pequeno porte: a percepção dos gestores. Revista Engenharia Sanitária Ambiental, v.18, n.4, p.341-348, 2013. https://doi.org/10.1590/S1413-41522013000400006

MACIEL, A. B. C.; FELIPE, J. A.; LIMA, Z. M. C. Os problemas de saneamento e seus impactos sobre a saúde pública do município de Dona Inês/PB. Revista Geografia em Debate, v.9, n.3, p.524-541, 2015.

MAGALHÃES, R. C.; ANDRADE, C. F.; OLIVEIRA, J. N.; MANJATE, E. S. Avaliação de políticas públicas de saneamento: o caso do Programa Minas Trata Esgoto. Monografias Ambientais, v.14, n.1, p.62-75, 2015. https://doi.org/10.5902/2236130816318

MARCHI, C. M. D. F.; MENDES, V. L. P. S. Gestão do saneamento básico: democracia representativa e participação social em um município da região metropolitana de Salvador - Bahia. Revista Brasileira de Gestão e Desenvolvimento Regional, v.14, n.1, p.110-134, 2018.

MEDEIROS, A. B.; MENDONÇA, M. J. S. L.; SOUS, G. L. S.; OLIVEIRA, I. P. A Importância da educação ambiental na escola nas séries iniciais. Revista Faculdade Montes Belos, v.4, n.1, p.1-17, 2011.

MELLO, M. C. C.; REZENDE, S. O conselho municipal de saneamento de Belo Horizonte: desafios e possibilidades. Revista Engenharia Sanitária Ambiental, v.19, n.4, p.479-488, 2014.

https://doi.org/10.1590/S1413-41522014019000000468

MENDES, T. M.; BARCELLOS, C. A dimensão territorial do esgotamento sanitário: o caso do Recreio dos Bandeirantes, Rio de Janeiro, Brasil. Revista Ciência e Saúde Coletiva, v. 23, n.2, p.647-658, 2018. https://doi.org/10.1590/1413-81232018232.27732015

MONTEIRO, D. C.; SARTORELI, C.; CORTESE, T. T. P.; SHIBAO, F. Y. Esgotamento sanitário: o caso do município de São Paulo. Revista Nacional de Gerenciamento de Cidades, v.6, n.37, p.88-102, 2018. https://doi.org/10.17271/2318847263720181747

$\begin{array}{llllll}\text { Caminhos de Geografia } & \text { Uberlândia-MG } & \text { v. 23, n. } 85 & \text { fev./2022 } & \text { p. } 69-87 & \text { Página } 85\end{array}$


NIRAZAWA, A. N.; OLIVEIRA, S. V. W. B. Indicadores de saneamento: uma análise de variáveis para elaboração de indicadores municipais. Revista de Administração Pública, v.54, n.4, p.753-763, 2018. https://doi.org/10.1590/0034-7612168118

NUNES, M. R.; PHILIPPI JUNIOR, A.; FERNANDES, V. A Atuação de conselhos do meio ambiente na gestão ambiental local. Revista Saúde e Sociedade, v.21, n.3, p.48-60, 2012.

https://doi.org/10.1590/S0104-12902012000700005

OCDE - Organização para a Cooperação e Desenvolvimento Econômico. Benefits of investing in water and sanitation: an OECD perspective. Paris: OECD Publishing, 2011.

PAIVA, R. F. P. S.; SOUZA, M. F. P. Associação entre condições socioeconômicas, sanitárias e de atenção básica e a morbidade hospitalar por doenças de veiculação hídrica no Brasil. Cadernos de Saúde Pública, v.34, n.1, p.1-11, 2018. https://doi.org/10.1590/0102-311x00017316

PEIXOTO, J. B. Saneamento básico: política, marco legal e instrumentos de gestão dos serviços. Brasília: UNESCO/Ministério das Cidades/Fundação Vale, 2013.

PEREIRA, T. T.; HELLER, L. Planos de saneamento básico: avaliação de 18 casos brasileiros. Revista Engenharia Sanitária Ambiental, v.20, n.3, p.395-404, 2015. https://doi.org/10.1590/S1413$\underline{41522015020000098824}$

PINHEIRO, A. P.; SAVOIA, J. R. F.; ÂNGELO, C. F. Análise comparativa da atuação de prestadores de serviços de saneamento públicos e privados no Brasil. Brazilian Business Review. v.13, n.1, p.118-140, 2016.

PITERMAN, A.; HELLER, L.; REZENDE, S. C. (A falta de) controle social das políticas municipais de saneamento: um estudo em quatro municípios de Minas Gerais. Saúde e Sociedade, v.22, n.4, p.11801192, 2013. https://doi.org/10.1590/S0104-12902013000400019

PRODANOV, C. C.; FREITAS, E. C. Metodologia do trabalho científico: métodos e técnicas da pesquisa e do trabalho acadêmico. Novo Hamburgo: Feevale, 2013.

REIS, D. A.; ESPERIDIÃO, F.; JORGE, M. A.; RIBEIRO, L. C. S.; MOTA, T. S.; SANTOS, J. C. N.; SILVA, A. T. Estudo bibliométrico da produção científica nacional e internacional no setor de saneamento. Revista Gestão, Inovação e Tecnologias, v.7, n.1, p.3669-3685, 2017. https://doi.org/10.7198/S2237$\underline{072220170001007}$

REZENDE, S. C.; HELLER, L. O saneamento no Brasil: políticas e interfaces. Rio de Janeiro: ABES, 2008.

SACHO, S. D.; HORA, K. E. Panorama do saneamento básico na Região Metropolitana de Goiânia. Revista Desenvolvimento em Questão, v.15, n.41, p.498-522, 2017. https://doi.org/10.21527/22376453.2017.41.498-522

SCARATTI, D.; MICHELON, W.; SCARATTI, G. Avaliação da eficiência da gestão dos serviços municipais de abastecimento de água e esgotamento sanitário utilizando Data Envelopment Analysis. Revista Engenharia Sanitária Ambiental, v.18, n.4, p.333-340, 2013. https://doi.org/10.1590/S1413$\underline{41522013000400005}$

SILVA, E. A.; MOITA NETO, J. M. Saneamento básico como dignidade humana: entre o mínimo existencial e a reserva do possível. Revista Engenharia Sanitária e Ambiental, v.24, n.3, p.493-500, 2019. https://doi.org/10.1590/s1413-41522019183905

SILVA, G. F. N.; HORA, K. E. R. O plano diretor municipal e sua interface com a drenagem urbana. Revista Labverde, n.7, p.143-167, 2013. https://doi.org/10.11606/issn.2179-2275.v0i7p142-167

SILVEIRA, R. B.; HELLER, L.; REZENDE, S. Identificando correntes teóricas de planejamento: uma avaliação do Plano Nacional de Saneamento Básico (Plansab). Revista de Administração Pública, v.47, n.3, p.601-622, 2013. https://doi.org/10.1590/S0034-76122013000300004

SILVESTRE, H. C. Public-private partnership and corporate public sector organizations: alternative ways to increase social performance in the Portuguese water sector? Utilities Policy, v.22, p.41-49, 2012. https://doi.org/10.1016/.jup.2012.01.002

SIQUEIRA, M. S.; ROSA, R. S.; BORDIN, R.; NUGEM, R. C. Internações por doenças relacionadas ao saneamento ambiental inadequado na rede pública de saúde da região metropolitana de Porto Alegre, Rio 
Grande do Sul, 2010-2014. Epidemiologia, v.26, n.4, p.795-806, 2017. https://doi.org/10.5123/S1679$\underline{49742017000400011}$

SNIS - Sistema Nacional de Informações sobre Saneamento. Diagnóstico dos serviços de água e esgoto. Brasília: SNIS, 2017.

SOARES, A. M. A regulação por consórcio público na prestação do serviço de saneamento. Revista Jurídica da Procuradoria-Geral do Distrito Federal, Brasília, v.39, n.2, p.197-207, 2014.

SODRÉ, F. F.; BRANDÃO, C. C. S.; VIZZOTTO, C. S.; MALDANER, A. O. Epidemiologia do esgoto como estratégia para monitoramento comunitário, mapeamento de focos emergentes e elaboração de sistemas de alerta rápido para COVID-19. Química Nova, v.43, n.4, p.515-519, 2020. https://doi.org/10.21577/0100-4042.20170545

SOUSA, C. S. S.; SOUSA, S. C. S.; ALVARES, A. M. Diretrizes normativas para o saneamento básico no Brasil. Caderno de Geografia, v.25, n.43, p.102-115, 2015. https://doi.org/10.21577/0100$\underline{4042.20170545}$

SOUZA, C. M. N. Participação dos cidadãos e saneamento básico: panorama da legislação nacional. Revista do instituto de Estudos Brasileiros, n.63, p.141-158, 2016. https://doi.org/10.11606/issn.2316901X.v0i63p141-158

SOUZA, C. M. N.; HELLER, L. O controle social em saneamento e em saúde: análise comparativa com base nos marcos legais federais brasileiros. Ciência \& Saúde Coletiva, v.24, n.1, p.285-294, 2019. https://doi.org/10.1590/1413-81232018241.35012016

SOUZA, V. C. B. Gestão da drenagem urbana no Brasil: desafios para a sustentabilidade. Gestão e Tecnologias Ambientais, v.1, n.1, p.057-072, 2013. https://doi.org/10.17565/gesta.v1i1.7105

SOUZA, V. C. B; MORAES, L. R. S.; BORJA, P. C. Contribuição para a definição de déficit em drenagem e manejo de águas pluviais urbanas. In: Exposição de experiências municipais em saneamento da associação nacional dos serviços municipais de saneamento, 16, 2012, Maringá. Anais... Maringá: ASSEMAE, 2012.

TEIXEIRA, J. C.; OLIVEIRA, G. S.; VIALI, A. M.; MUNIZ, S. S. Estudo do impacto das deficiências de saneamento básico sobre saúde pública no Brasil no período de 2001 a 2009. Revista Engenharia Sanitária Ambiental, v.19, n1, p.87-96, 2014. https://doi.org/10.1590/S1413-41522014000100010

TISCHER, V. Magnitude do impacto do esgotamento sanitário no Brasil. Revista Gestão e Sustentabilidade Ambiental, v.6, n,3, p.358-379, 2017. https://doi.org/10.19177/rgsa.v6e32017358-379

YÉVENES-SUBIATRE, A. Prospectiva y estrategia en el escenario contemporáneo. Latin American Journal of International Affairs, v.2, n.3, p.90-106, 2010.

ZHOU, X. Z.; LIA, Z.; ZHENGB, T.; YANA, Y.; LIB, P.; ODEYA, E. A.; MANGA, H. P.; UDDIND, S. M. N. Review of global sanitation development. Environment International, n.120, p. 246-261, 2018. https://doi.org/10.1016/i.envint.2018.07.047

ZIKMUND, W.G. Business research methods. Fort Worth: Dryden, 2000.

Recebido em: 17/09/2020

Aceito para publicação em: 10/11/2021 